\title{
Analysis of Heavy Metals in Human Scalp Hair Using Energy Dispersive X-Ray Fluorescence Technique
}

\author{
Peter O. Onuwa*, Lami A. Nnamonu, Ishaq S. Eneji, Rufus Sha’Ato \\ Department of Chemistry and Centre for Agrochemical Technology, University of Agriculture, Makurdi, Benue State, Nigeria. \\ Email: "peteronuwa@yahoo.com
}

Received October $6^{\text {th }}, 2012$; revised November $18^{\text {th }}, 2012$; accepted November $27^{\text {th }}, 2012$

\begin{abstract}
Analysis of six heavy metals $(\mathrm{Cr}, \mathrm{Mn}, \mathrm{Ni}, \mathrm{Cu}, \mathrm{Zn}$ and $\mathrm{Mo})$ in human scalp hair was carried out among various occupational distributions to ascertain their heavy metal burden, using energy dispersive $\mathrm{x}$-ray fluorescence technique (ED$\mathrm{XRF})$. The result of the analysis shows that mean concentrations $(\mathrm{mg} / \mathrm{kg})$ of heavy metals obtained were as follows: $\mathrm{Cr}=$ $17.1 \pm 12.7 ; \mathrm{Mn}=3.11 \pm 0.50 ; \mathrm{Ni}=11.3 \pm 9.3 ; \mathrm{Zn}=451 \pm 128 ; \mathrm{Cu}=83.3 \pm 35.8$ and $\mathrm{Mo}$ is $9.16 \pm 9.1$. While the mean concentrations of $\mathrm{Cr}, \mathrm{Cu}$, and $\mathrm{Mo}$ were higher in the females, that of $\mathrm{Mn}, \mathrm{Ni}$ and $\mathrm{Zn}$ were more in the males. Statistical analysis of the results for both genders at 0.05 probably shows significant difference for $\mathrm{Ni}, \mathrm{Zn}$ and $\mathrm{Mo}$ while $\mathrm{Cr}, \mathrm{Mn}$ and $\mathrm{Cu}$ showed no significant difference. The relationships between age, body mass, height, and heavy metal concentrations were also investigated. Statistical analysis of the results indicates that there was no correlation between the body mass $\left(\mathrm{R}^{2} \leq 0.048\right)$, height $\left(\mathrm{R}^{2} \leq 0.002\right)$ and heavy metal concentration in hair. Zn showed the highest deviation among other elements in the individual samples for both genders which reflect the individual variation in the concentration of $\mathrm{Zn}$.
\end{abstract}

Keywords: Human Hair; Heavy Metals; X-Ray Fluorescence; Risk Assessment

\section{Introduction}

Hair is a site of excretion for essential, nonessential and potentially toxic elements. The amount of an element that is irreversibly incorporated into growing hair is proportional to the level of the element in other body tissues [1]. Therefore, hair analysis may provide an indirect screening test for physiological excess and deficiency of elements in the body. Clinical research indicates that hair levels of specific elements, particularly potentially toxic elements are highly correlated with pathological disorders. For such elements, levels in hair may be more indicative of body stores than the levels in blood and urine. Comparing hair-analysis with blood- or urine-analysis with the same purpose, a couple of factors such as simplicity of matrix, relatively high concentration of trace elements, easier sample gathering, transfer and storage should be considered [2,3]. Previous investigation has shown that high concentration of heavy metal in the hair indicates that the person is contaminated by that heavy metal. Although, blood or urine analysis may exhibit normal concentration level even though sample is gathered in the same time as hair, the analytical results for hair analysis should be observed more carefully [4]. Hair

${ }^{*}$ Corresponding author. is not only a good index of exposure to elements because of the partitioning, it also allows for a non-invasive biological sample collection [5].

Heavy metal contamination requires adequate attention because of sporadic outbreak of epidemics and other endemic illnesses.

Although, some heavy metals were required in trace amounts to maintain the metabolism of the human body, especially iron that is an important component of haemoglobin - the pigment that transports oxygen in the red blood cells. Others such as $\mathrm{Mn}, \mathrm{Ni}, \mathrm{Cu}, \mathrm{Zn}$ etc are essential micronutrients for life processes in plants and micro-organisms. Deadly diseases like oedema of eyelids, tumour, and congestion of the nasal membrane, muscular, reproductive, neurological, and genetic malfunction were caused by some of these heavy metals [6]. Apart from natural sources, significant amount of heavy metals in the soil come from anthropogenic activities [7]. Research has shown that $\mathrm{Cr}$ concentration may be partly attributed to the $\mathrm{Cr}$ content in tobacco leaves, from the soil and this may be more in smokers [8]. Researchers have found many correlations of essential elements to diseases, metabolic disorders, nutritional status etc. [9]. Hence, monitoring of heavy metals from human hair has been of interest to researchers in the fields of environmental chem- 
istry and medical science because the amount of heavy metals of hair samples can reflect the nutritional state of the person or the environment where that person resides or works [4]. Many analytical techniques such as atomic absorption spectrometry (AAS), inductively coupled plasma atomic emission spectrometry (ICP-AES), x-ray fluorescence, neutron activation analysis (NAA) and protoninduced $\mathrm{x}$-ray emission (PIXE) have been widely used for analysis of hair samples [4]. In this research, energy dispersive $\mathrm{x}$-ray fluorescence technique (EDXRF) was used for analysis of six (6) heavy metals $(\mathrm{Cr}, \mathrm{Mn}, \mathrm{Ni}, \mathrm{Cu}$, $\mathrm{Zn}$ and Mo) in human scalp hair due to its high sensitivity, low detection limit and as well as minimal loss of analyte of interest during digestion processes in the conventional method of AAS.

\section{Materials and Method}

\subsection{Sampling}

Freshly cut human scalp hair samples were collected from 50 individuals between the ages of $7-55$ years (male and female) and across several occupational distributions within Makurdi town in Central Nigeria (latitude $7^{\circ} 44^{\prime} \mathrm{N}$ and longitude $8^{\circ} 31^{\prime} \mathrm{E}$ ). The samples were quickly put in a pre-coded polythene bag, sealed tightly and kept for pre-treatment. A questionnaire was given to each respondent which contained a highlight of information on gender, age, occupation, population density of residential area, type of food consumed, water source, presence of refuse dump, behavioural pattern etc. prior to sample collection. Height and body mass of respondent were also measured and recorded alongside sample hair code at the time of collection.

\subsection{Sample Cleaning}

The hair samples collected were cut to about $200-250$ $\mathrm{mg}$ by using stainless steel scissors rinsed in ethanol, then coded and stored. The stored samples were further cut into approximately $0.3 \mathrm{~cm}$ pieces and mixed to allow a representative sub sampling. These were washed according to the recommendation of International Atomic Energy Agency (IAEA) [10]: first in ethanol once, then three times in distilled water, once again in ethanol and followed finally in distilled water, accordingly. They were placed in crucibles and dried in the oven at $75^{\circ} \mathrm{C} \pm$ $5^{\circ} \mathrm{C}$ for $15-25$ minutes. About $0.1065 \mathrm{~g}$ of pre-treated hair sample was weighed using analytical balance $(A B$ 54-S METTLER TOLEDO Model from Switzerland) and stored in an inert plastic container of about $10 \mathrm{~cm}^{3}$ capacity, corked tightly and kept for EDXRF analysis.

\section{Instrumentation and Procedure}

The analysis was carried out in the XRF laboratory at the
Centre for Energy Research and Training (CERT), Zaria, Kaduna State, Nigeria, using a Minipal 4 PW 4030/42B $\mathrm{x}$-ray fluorescence with molybdenum tube and spinner. Minipal is a compact energy dispersive x-ray spectrometer designed for the elemental analysis of a wide range of samples. The system is controlled by a PC running the dedicated Minipal analytical soft ware. The Minipal 4 version in use is an energy dispersive micro processor controlled analytical instrument designed for the detection and measurement of elements in a sample (solids, powders and liquids) from sodium to uranium. The weighed samples for EDXRF analysis were ground in an agate mortar and a binder (PVC dissolved in toluene) was added to the sample, carefully mixed and pressed in a hydraulic press into a pellet. The pellet was loaded in the sample chamber of the spectrometer and voltage $(30 \mathrm{kV})$ and a current $(1 \mathrm{~mA})$ applied to produce the $\mathrm{x}$-rays to excite the sample for a preset time of 10 minutes. The spectrum from the sample was then analysed to determine the concentration of the elements in the sample. The Minipal 4 x-ray had an excitation system of $30 \mathrm{KV}$ maximum, a minimum and maximum current of $1 \mu \mathrm{A}, 1$ $\mathrm{mA}$ respectively with a power rating of $9 \mathrm{~W}$. It is fitted with thin film circle sample support (cup) with diameter of $63.5 \mathrm{~mm}$ where the pelletised hair sample was placed. The primary beam filters were arranged in twelve positions for optimum function across the periodic table. Eleven beam filters were filled with hair sample while the twelfth position the certified reference material (CRM) hair. The XRF had silicon-lithium (Si-Li) diode detector. The collimator, the target and the source of radiation had close coupling to the detector which increases the versatility, and high x-ray output with lower power tube [10]. Quality assurance energy calibration was first performed. A quality control system was employed to ensure data quality by using a certified reference human hair (GBW 09101) obtained from Shanghai Institute of Nuclear Research, Academia, Sinica, Shanghai 201849, China. The CRM was placed in the twelfth position and run concurrently with each running of the hair sample for individual elemental concentration.

\section{Results and Discussion}

Variation of concentration of heavy metals in human hair can be attributed to human history [11]. Hence, individual's burden of heavy metal concentrations reflects the extent of the person's exposure to atmospheric pollutants, intakes of food and metabolism. The distribution pattern of various heavy metals among the males hair samples investigated is shown in Figure 1 while that of female is presented in Figure 2. The total mean concentration of individual heavy metals in males and females hair samples is presented in Table 4, which showed that the concentration of $\mathrm{Zn}$ is comparably higher than all the other 


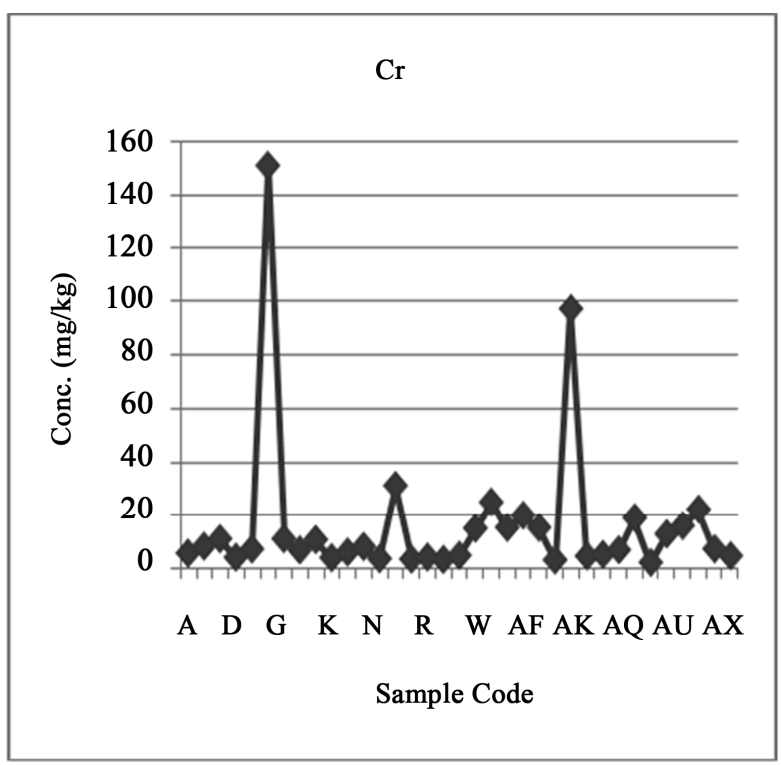

(a)

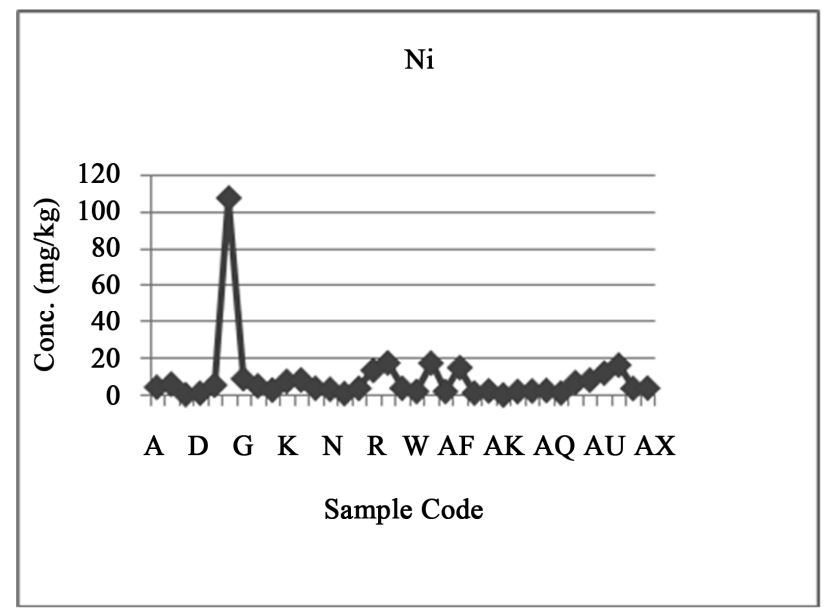

(c)

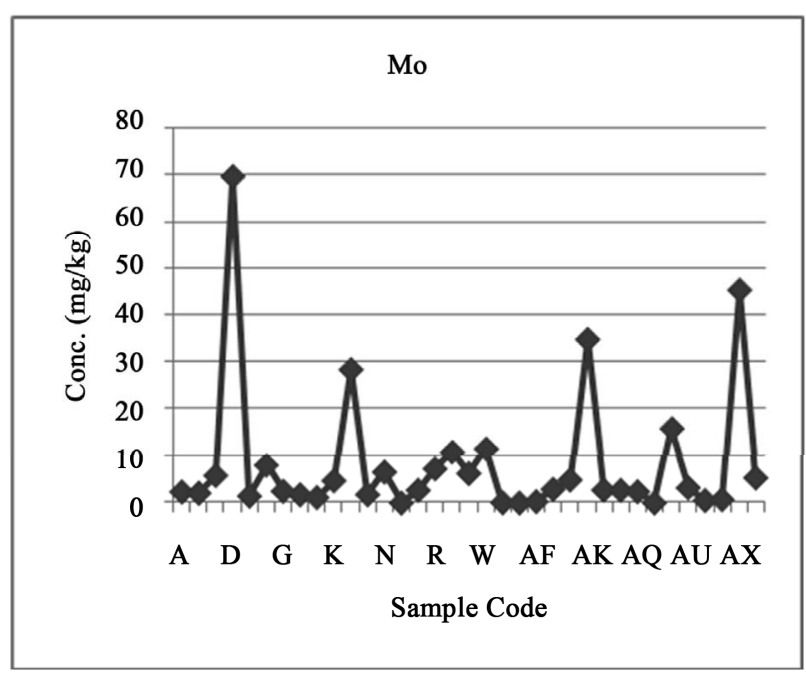

(e)

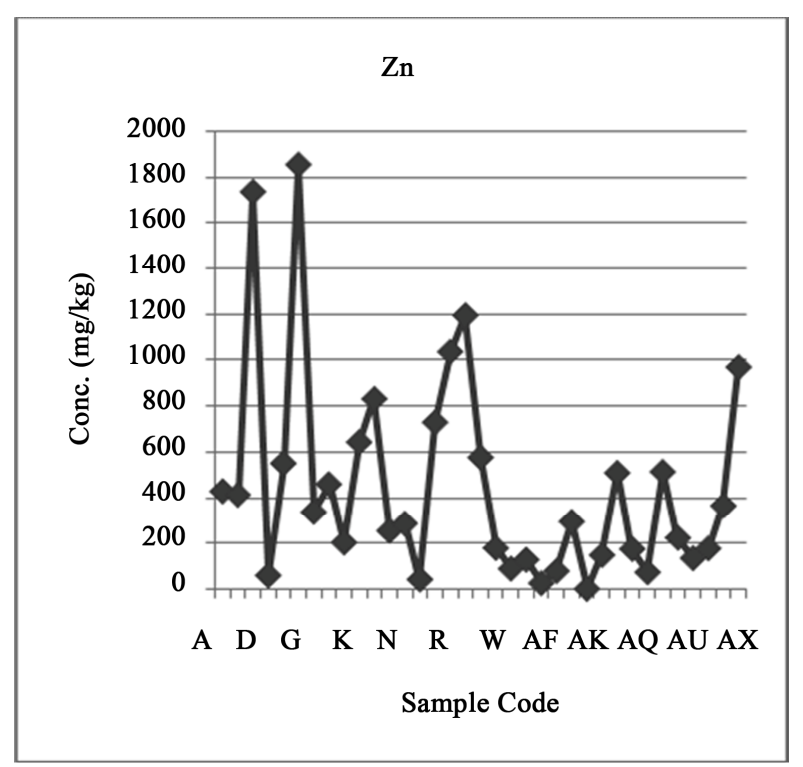

(b)

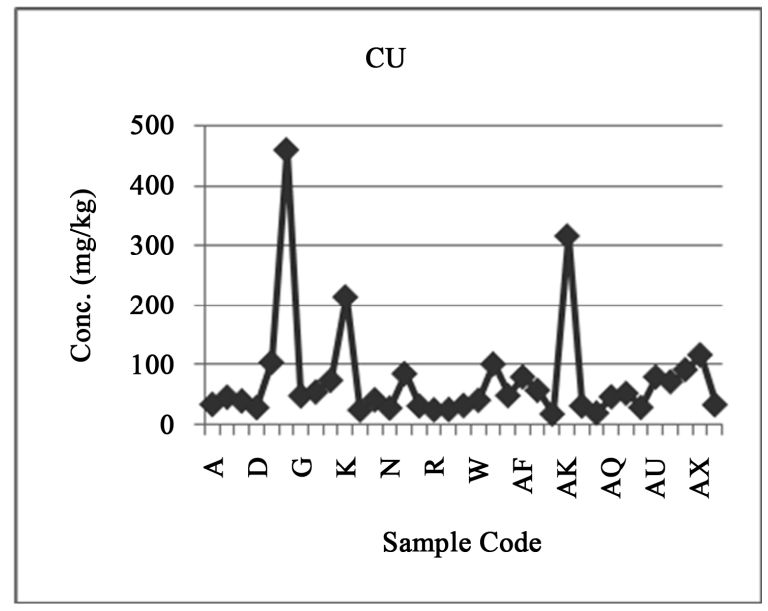

(d)

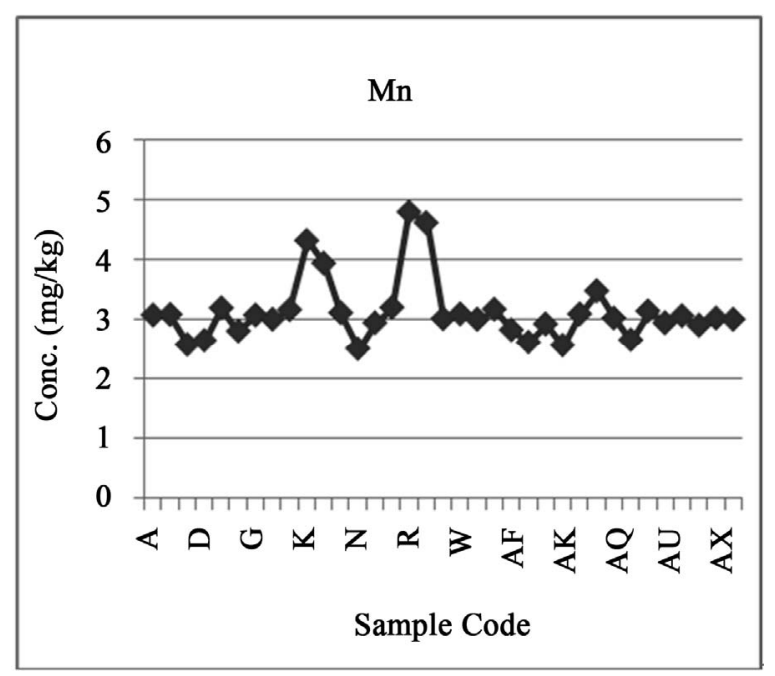

(f)

Figure 1. Mean concentration of individual heavy metals in hair samples from males. 


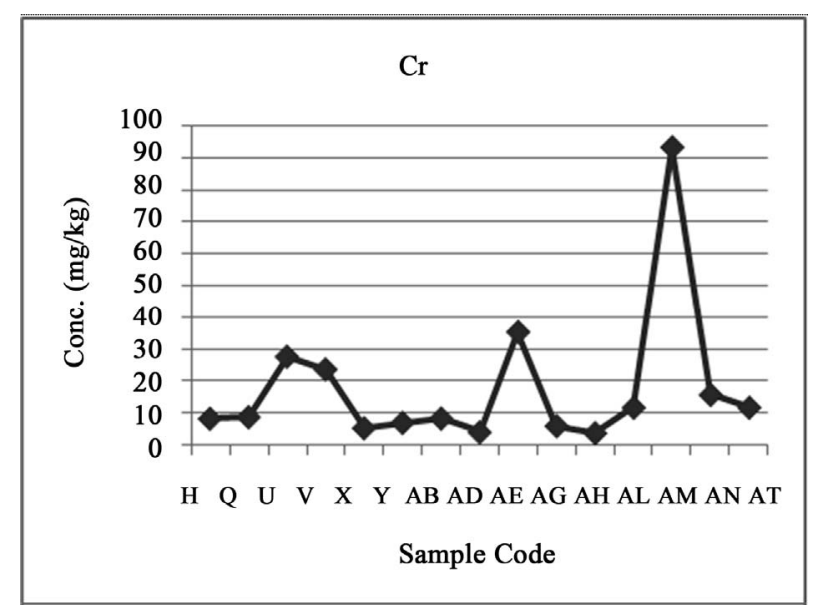

(a)

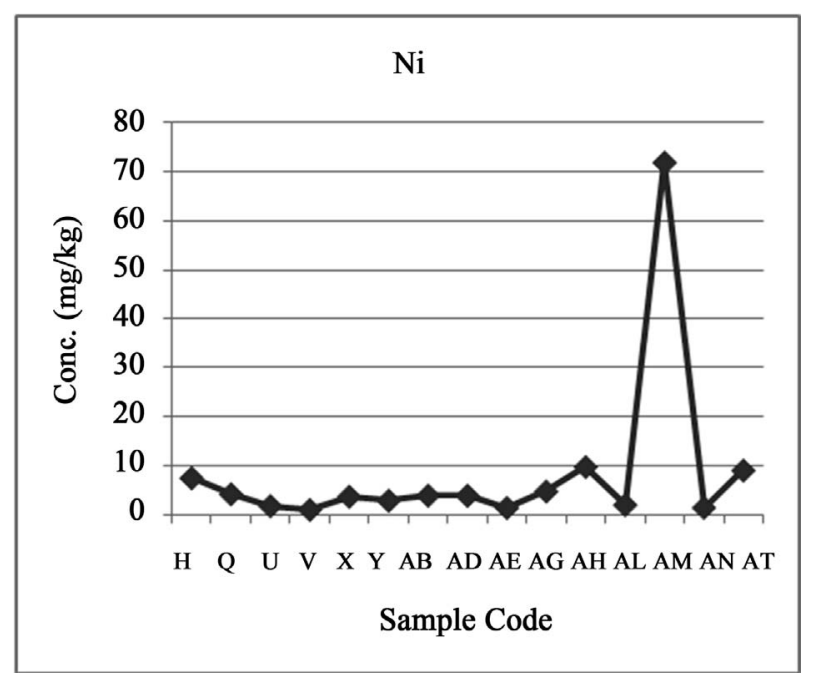

(c)

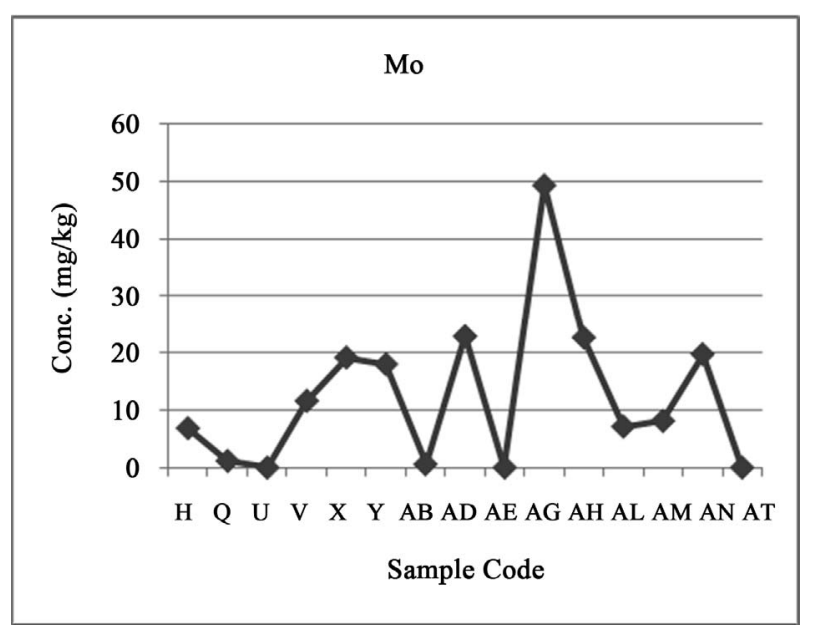

(e)

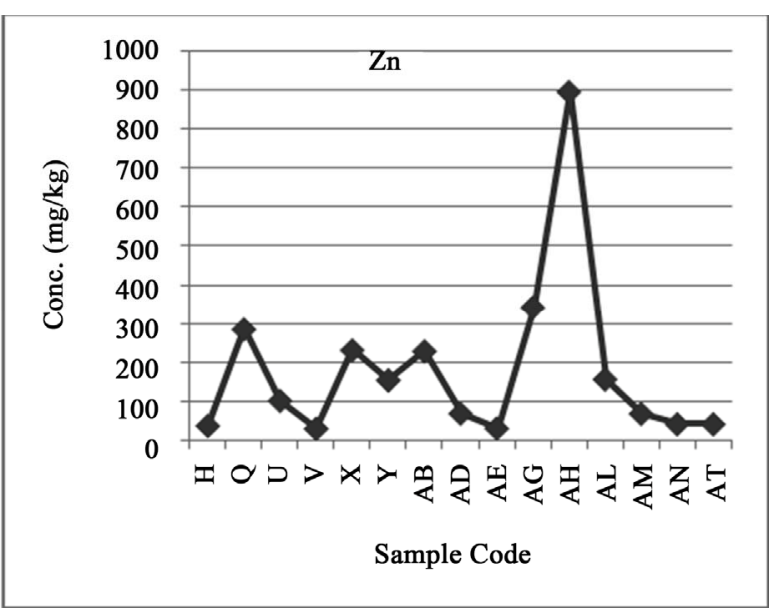

(b)

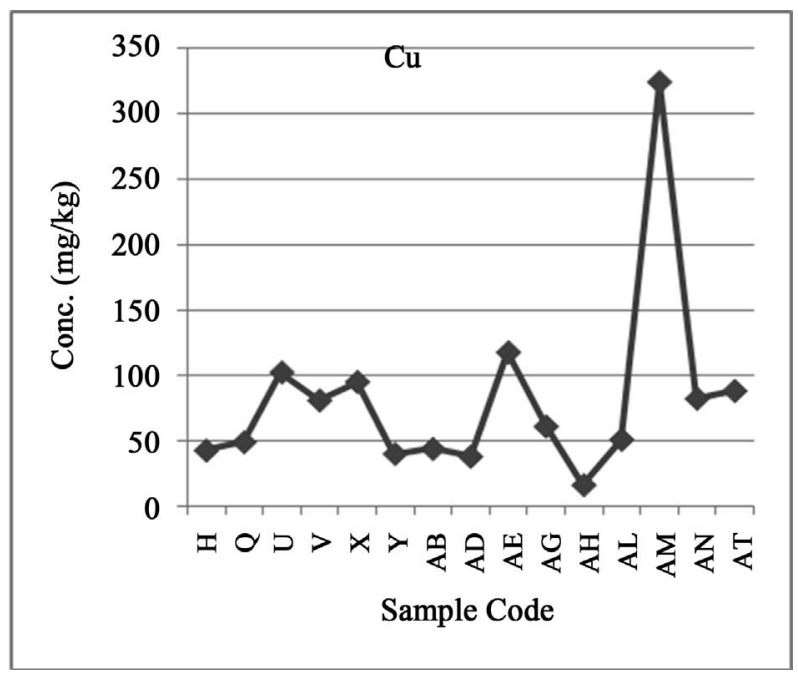

(d)

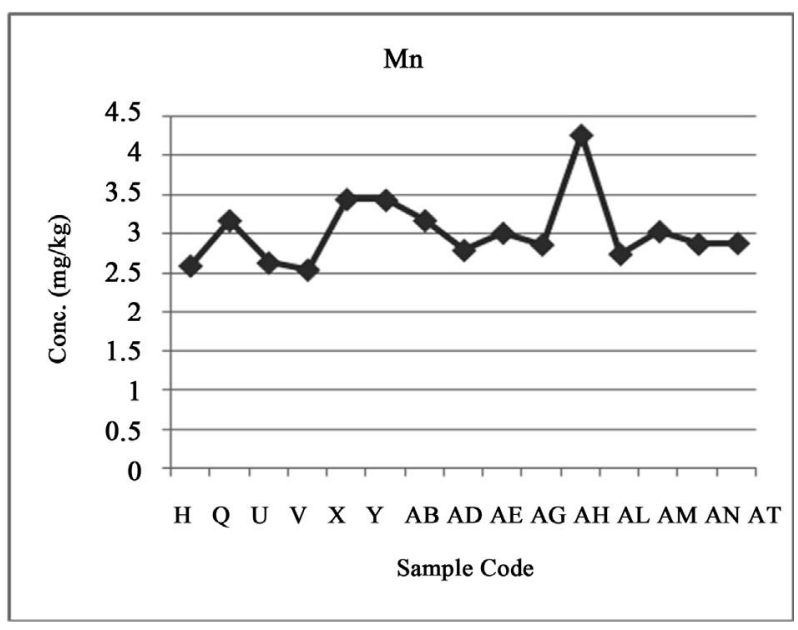

(f)

Figure 2. Mean concentration of individual heavy metals in hair samples from females.

elements while Mn has the least. There was however an outlier in the heavy metal concentration in sample code $\mathrm{F}$ in the males' hair sample for $\mathrm{Cr}, \mathrm{Ni}, \mathrm{Zn}$ and $\mathrm{Cu}$ which were $151.2,107.9,1,850.1$ and $460.1(\mathrm{mg} / \mathrm{kg})$ respectively as shown in Figure 1. This might be related to the nature of the individual's work, which also has the long- 
est exposure time based on the completed questionnaire. Sample AM showed higher peaks for $\mathrm{Cr}, \mathrm{Ni}$, and $\mathrm{Cu}$; samples $\mathrm{AH}$ was higher in concentration of $\mathrm{Mn}$ and $\mathrm{Zn}$ while AG was higher for Mo concentration in females' hair samples as shown in Figure 2.

The analytical process for the analysis of heavy metals in human hair was carried out successive to the analysis of the certified sample with each cycle of beam filter arrangement. The adjusted value was used as a factor for converting the concentrations of other samples analysed. The relationships between age, body mass, height and heavy metal concentrations were investigated. Statistical analysis of the results indicates that there was no correlation between the body mass $\left(\mathrm{R}^{2} \leq 0.048\right)$, height $\left(\mathrm{R}^{2} \leq\right.$ 0.002 ) and heavy metal concentration in hair. However, it is generally believed that the amount of heavy metals in human body should correlate with age as a result of bioaccumulation $[11,12]$. These toxic metals have relationship with duration of exposure (age) since their effects are cumulative [13]. Tables 1 and 2 indicate the age distribution for concentration of heavy metals under investigation between male and female genders. The mean concentrations of heavy metals for the fifty samples are presented in Table 3.
Zn showed the highest concentrations $(\mathrm{mg} / \mathrm{kg})$ in both genders between ages $7-20$ with values of $646 \pm 297$ $(\mathrm{mg} / \mathrm{kg})$ and $384 \pm 361$ for males and females respectively. While Mo has the lowest value of $2.47 \pm 2.1(\mathrm{mg} /$ $\mathrm{kg}$ ) for males and Mn was $2.88 \mathrm{mg} / \mathrm{kg}$ for females. Table 4 shows their total distribution in which $\mathrm{Zn}$ has the highest over all concentration of $451 \pm 128 \mathrm{mg} / \mathrm{kg}$ while $\mathrm{Mn}$ has the over all lowest value of $3.11 \mathrm{mg} / \mathrm{kg}$ for this analysis method. Afridi et al. [14] reported values of $224.0 \pm$ 7.07 and $214.14 \pm 8.2 \mathrm{mg} / \mathrm{kg}$ for $\mathrm{Zn}$ between the ages 30 45 and 46 - 60 years respectively using flame atomic absorption spectrometer (FAAS) to analysed scalp hair of non hypertensive group. The value of $\mathrm{Ni}$ within age range of $32-42$ years for this work is $7.54 \mathrm{mg} / \mathrm{kg}$. Ni was also reported to be $6.79 \mathrm{mg} / \mathrm{kg}$ for ages $30-45$ years in a similar biological matrix i.e. human hair [14]. Table 4 shows heavy metal distribution $(\mathrm{mg} / \mathrm{kg})$ in 50 human hair samples. Some elements such as $\mathrm{Zn}, \mathrm{Cr}, \mathrm{Mn}, \mathrm{Cu}$ and Mo are important in human nutrition. These elements are also present in pharmaceutical products. This is because a wide variety of metals mostly transition elements are employed as complexes or salts to act as catalysts, therefore, any pharmaceutical excipient whose synthesis involves the use of one or more metal catalysts may

Table 1. Age distribution and level of heavy metals in male hair samples.

\begin{tabular}{cccccccc}
\hline \multirow{2}{*}{ Range (years) } & \multirow{2}{*}{ Number of male } & \multicolumn{5}{c}{ Heavy } & \multicolumn{2}{c}{ Metals (mg/kg) } \\
\cline { 3 - 8 } & & Cr & Mn & Ni & Cu & Zn & Mo \\
\hline $7-20$ & 4 & $5.77 \pm 1.1$ & $3.27 \pm 0.5$ & $5.59 \pm 2.2$ & $50.9 \pm 43.4$ & $646 \pm 297$ & $20.3 \pm 20.3$ \\
$21-31$ & 19 & $14.8 \pm 21.5$ & $3.16 \pm 0.6$ & $5.55 \pm 5.4$ & $57.6 \pm 66.4$ & $356 \pm 341$ & $8.9 \pm 16.8$ \\
$32-42$ & 7 & $10.3 \pm 5.7$ & $3.16 \pm 0.6$ & $7.54 \pm 5.1$ & $85.0 \pm 61.4$ & $523 \pm 579$ & $2.47 \pm 2.1$ \\
$\geq 43$ & 5 & $39.2 \pm 63.0$ & $2.92 \pm 0.1$ & $7.54 \pm 5.1$ & $140 \pm 181$ & $600 \pm 707$ & $3.71 \pm 2.9$ \\
\hline
\end{tabular}

Table 2. Age distribution and level of heavy metals in female hair samples.

\begin{tabular}{cccccccc}
\hline \multirow{2}{*}{ Range (years) } & \multirow{2}{*}{ Number of female } & \multicolumn{5}{c}{ Heavy } & Metals (mg/kg) \\
\cline { 3 - 8 } & & Cr & Mn & Ni & Cu & Zn & Mo \\
\hline $7-20$ & 4 & $5.74 \pm 2.1$ & $3.27 \pm 0.7$ & $5.52 \pm 2.8$ & $40.2 \pm 18.5$ & $384 \pm 361$ & $23.8 \pm 19.9$ \\
$21-31$ & 10 & $23.8 \pm 26.3$ & $2.95 \pm 0.3$ & $9.72 \pm 21.9$ & $98.8 \pm 83.7$ & $113 \pm 91$ & $9.17 \pm 7.7$ \\
$32-42$ & 0 & - & - & - & - & - & - \\
$\geq 43$ & 1 & 11.0 & 2.88 & 8.97 & 88.4 & 40.7 & - \\
\hline
\end{tabular}

Table 3. Age distribution and level of heavy metals in the 50 hair samples.

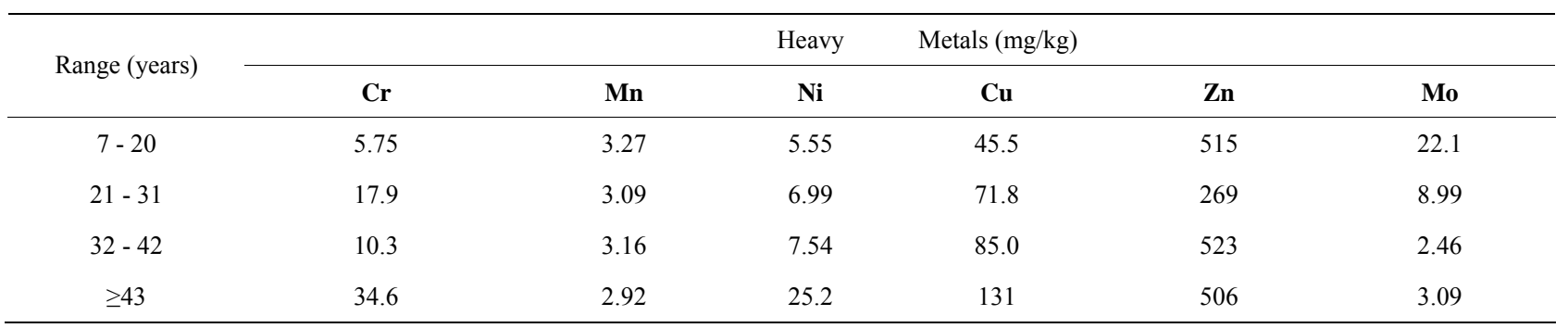


Table 4. Heavy metal distribution in 50 hair samples.

\begin{tabular}{cccc}
\hline $\begin{array}{c}\text { Heavy metals } \\
(\mathrm{mg} / \mathrm{kg})\end{array}$ & Male & Female & Total average \\
\hline $\mathbf{C r}$ & $17.52 \pm 14.9$ & $13.81 \pm 9.18$ & $17.1 \pm 12.7$ \\
$\mathbf{M n}$ & $3.13 \pm 0.15$ & $3.03 \pm 0.21$ & $3.11 \pm 0.5$ \\
$\mathbf{N i}$ & $6.56 \pm 19.14$ & $8.07 \pm 2.24$ & $11.3 \pm 9.3$ \\
$\mathbf{C u}$ & $83.4 \pm 40.5$ & $75.8 \pm 31.3$ & $83.3 \pm 35.8$ \\
$\mathbf{Z n}$ & $531 \pm 127$ & $179 \pm 181$ & $451 \pm 128$ \\
$\mathbf{M o}$ & $9.26 \pm 8.18$ & $17.6 \pm 8.18$ & $9.16 \pm 9.1$ \\
\hline
\end{tabular}

contain residual metal(s) in form of the original catalyst(s) or as derivative [13]. This may accumulate in human body when taken which may add to this metal content in the body.

Zinc showed the highest deviation among other elements in the individual samples for both genders which reflects the individual variation in the concentration of $\mathrm{Zn}$. Mo showed the highest coefficient of variation while $\mathrm{Mn}$ indicated the least. This implies that $\mathrm{Mn}$ is more closely distributed among the individual samples than $\mathrm{Ni}$ and other elements discussed. The mean concentration of heavy metals in both males and females were compared statistically at 0.05 probability for the method used. Significant difference was found between both genders $(\mathrm{P}>$ 0.05 ) for $\mathrm{Ni}, \mathrm{Zn}$ and $\mathrm{Mo}$ while $\mathrm{Cr}, \mathrm{Mn}$ and $\mathrm{Cu}$ showed no significant difference.

There was observed variations in the concentration of individual elements in both genders with the highest found among the females for Mo and $\mathrm{Ni}$ but $\mathrm{Cr}, \mathrm{Mn}, \mathrm{Cu}$ and $\mathrm{Zn}$ were more distributed in the male population. The exposure of hair to the environment and the chemical treatment of hair for cosmetic purposes, which leads to increase or decrease in metal concentration (external contamination) could account for this observation $[15,16]$. It was also asserted that there is personal difference in concentrations of heavy metals in the human hair according to human life or history such as occupation, sex, age, food, habit, social condition [11]. Individual's deviation of heavy metal concentrations reflects the degree of environmental pollutants exposure to the human body and intakes of food. Meaning that, there is potential for human exposure to heavy metals from drinking contaminated water or eating fish from contaminated water bodies [17-19]. They are finally transferred to other animals including humans through the food chain.

\section{Conclusion}

Analysis of $\mathrm{Cr}, \mathrm{Mn}, \mathrm{Ni}, \mathrm{Cu}, \mathrm{Zn}$ and $\mathrm{Mo}$ in human hair has been carried out to ascertain the accumulation of heavy metals. The mean concentrations of heavy metals showed that all the 50 hair samples were contaminated with the elements investigated. The mean concentrations of $\mathrm{Ni}$ and Mo were determined to be higher in the females' samples while that of $\mathrm{Cr}, \mathrm{Mn}, \mathrm{Cu}$, and $\mathrm{Zn}$ were more in the males. Samples $\mathrm{F}$ showed higher values for $\mathrm{Cr}, \mathrm{Ni}, \mathrm{Zn}, \mathrm{Cu}$ and $\mathrm{D}$ for Mo respectively among male gender while samples $\mathrm{AM}, \mathrm{AH}$ and $\mathrm{AG}$ also showed higher values for $(\mathrm{Cr}, \mathrm{Ni}, \mathrm{Cu}),(\mathrm{Mn}, \mathrm{Zn})$ and Mo respecttively among female gender. These samples use the same means of cooking i.e. fire wood and similar sources of drinking water (well, bore hole, tap) and consume the same class of food, which actually reflect the life history, nutritional pattern as well as the environmental content of the individuals. The pattern of concentration of the heavy metals in the hair samples were in decreasing order of $\mathrm{Zn}>\mathrm{Cu}>\mathrm{Cr}>\mathrm{Ni}>\mathrm{Mo}>\mathrm{Mn}$.

\section{Acknowledgements}

Our appreciation goes to all the people that volunteered their hair samples for this research work without hesitation. We are also grateful to Centre for Energy Research and Training (CERT), Zaria, for opportunity given to us to use their XRF equipment. Finally, we thank all the anonymous reviewers for their useful comments.

\section{REFERENCES}

[1] J. E. Kaslow, "Hair Analysis: Cadmium Is Considered a Toxic Heavy Metal with No Known Metabolic Function in the Body," MD, FACP, FACAAI Physician and Surgeon Board Certified Internal Medicine, Santa Ana, 2011, p. 16.

[2] K. Bencze, "What Contribution Can Be Made to Biological Monitoring by Hair Analysis?" Fresenius' Journal of Analytical Chemistry, Vol. 338, No. 1, 1990, pp. 58-61. doi:10.1007/BF00322786

[3] D. Pozebon, V. L. Dressler and A. J. Curtius, "Hair Analysis: A Review on the Procedures for the Determination of Trace Elements and Applications," Química Nova, Vol. 22, No. 6, 1999, p. 838. doi:10.1590/S0100-40421999000600011

[4] R. S. Jung, S. R. Yang, J. K. Han, G. H. Kang and G. H. Lee, "Determination of Lead, Cadmium, and Chromium in Hair Optimised by Simplex Method Using Electrothermal Vaporization-Inductively Coupled Plasma Mass Spectrometry," Analytical Sciences, Vol. 17, 2001, pp. 999-1002.

[5] A. Johansen, "Environmental Health: Science, Policy and Social Justice Winter Quarter," Central Washington University, Ellensburg, 2010.

[6] P. Eck and L. Wilson, "Toxic Metal in Human Health and Disease,' Institute of Applied Nutrition and Bioenergetics, Ltd., Phoenix, 1989.

http://holisticvetpetcare.com/pdf/Heavy Metal Poison Hair Analysis-2.pdf

[7] T. Agusa, T. Kunito, E. Nakashima, T. B. Minh, S. Tanabe, A. Subramanian and P. H. Viet, "Preliminary Studies on Trace Element Contamination in Dumping Sites of 
Municipal Waste in Indian and Vietnam," Journal De Physique. IV, Vol. 107, No. 1, 2003, pp. 21-24.

[8] A. Sukumar and R. Subramanian, "Elements in Hair and Nails of Residents from a Village Adjacent to New Delhi: Influence of Place of Occupation and Smoking Habits," Biological Trace Element Research, Vol. 34, No. 1, 1992, pp. 99-105. doi:10.1007/BF02783902

[9] D. A. Bass, D. Hickok, D. Quig and K. Urek, "Trace Element Analysis in Hair: Factor Determining Accuracy, Precision and Reliability," Alternative Medicine Review, Vol. 6, No. 5, 2001, pp. 472-481.

[10] K. Jauharah, W. Husin, H. Imam, I. Norddin and A. A. Mohd, "Heavy Metals in Human Hair," International Journal of Physical Sciences, Vol. 6, No. 8, 2011, pp. 20902094.

[11] P. C. D. Lemos, H. M. Dung, C. Dong Vu, N. Thi Sy and N. M. Sinh, "Analysis of Angolan Human Hair Samples by the $\mathrm{K}_{\mathrm{o}}$-NAA Technique on the Dalat Research Reactor: The Study and Application on the $\mathrm{K}_{\mathrm{o}}$-Standardization Method of Neutron Activation Analysis at Dalat Nuclear Reasrch Institute (NRI), Vietnam," Proceedings of the 5th Asian Workshop on Utilization Research Reactors, Jabkarta, 2005.

[12] S. J. Steindel and P. J. Howanitz, "Uncertainty of Hair Analysis for Trace Metals," Journal of the American Medical Association, Vol. 285, No. 1, 2001, pp. 83-85. doi:10.1001/jama.285.1.83

[13] H. I. Afridi, T. G. Kazi, M. K. Jamali, G. H. Kazi, M. B. Arain, N. Jalbani and G. Q. Shar, "Analysis of Heavy Metals in Scalp Hair Samples of Hypertensive Patients by Conventional and Microwave Digestion Methods," Spec- troscopy Letters, Vol. 39, No. 2, 2006, pp. 203-214. doi: $10.1080 / 00387010500531266$

[14] "European Agency for the Evaluation of Medicinal Products (EMEA): Evaluation of Medecine for Human Use," London, 2002, p. 24. http://ec.europa.eu/environment/waste/studies/pdf/heavymetals report.pdf

[15] M. Wilhem, F. K. Ohnesorge, I. Lombeck and D. Hafner, "Uptake of Aluminium, Cadmium, Copper, Lead, and Zinc by Human Scalp Hair and Elution of the Adsorbed Metals," Journal of Analytical Toxicology, Vol. 13, No. 1, 1989, pp. 17-21.

[16] C. Jurado, P. Kintz, M. Menendez and M. Repetto, "Influence of the Cosmetic Treatment of Hair on Drug Testing," International Journal of Legal Medicine, Vol. 110, No. 3, 1997, pp. 159-163. doi:10.1007/s004140050056

[17] J. Andreji, I. Stránai, P. Massányi and M. Valent, "Concentration of Selected Metals in Muscle of Various Fish Species," Journal of Environmental Science and Health, Part A, Vol. 40, No. 4, 2005, pp. 899-912.

[18] M. B. Mokhtar, "Assessment Level of Heavy Metals in Penaeus monodon and Oreochromis spp in Selected Aquaculture Ponds of High Densities Development Area," Journal of Scientific Research, Vol. 30, No. 3, 2009, pp. 348360.

[19] I. S. Eneji, R. Sha'Ato and P. A. Annune, "Bioaccumulation of Heavy Metals in Fish (Tilapia zilli and Clarias gariepinus) Organs from River Benue, North-Central Nigeria," Pakistan Journal of Analytical and Environmental Chemistry, Vol. 12, No. 1-2, 2011, pp. 25-31. 